\title{
Preface to Special Issue
}

\section{Atmospheric Chemistry and Physics at Mountain Sites 2017}

\section{Guest Editors}

Dr. Shiro Hatakeyama, Center for Environmental Science in Saitama, Japan (Present address: Asia Center for Air Pollution Research, Japan) (hatashir@cc.tuat.ac.jp)

Prof. Yasuhito Igarashi, Meteorological Research Institute, Japan (igarashi.yasuhito.4e@kyoto-u.ac.jp)

Prof. Johannes Stähelin, ETH Zürich, Switzerland (johannes.staehelin@env.ethz.ch)

Prof. Gannet Hallar, Desert Research Institute, USA (gannet.hallar@utah.edu)

Prof. Ta-Chih Hsiao, National Taiwan University, Taiwan (tchsiao@ncu.edu.tw)

\section{Overseeing Editor-in-Chief}

Prof. Daniel A. Jaffe, University of Washington-Bothell, USA

(djaffe@uw.edu)

It is well recognized that air pollution is not only a local environmental problem related to human health but also a regional-global problem closely related to global warming - climate change. $\mathrm{PM}_{2.5}$ including black carbon particles and tropospheric ozone are assumed to be important constituents known as SLCP (short-lived climate pollutants). Emission of those pollutants as well as their source compounds such as $\mathrm{NO}_{\mathrm{x}}, \mathrm{VOCs}$, and $\mathrm{SO}_{2}$ affects the environment of the source country, surrounding countries, and moreover, whole northern hemisphere by long-range trans-boundary transport. Such long-range transport often takes place through free troposphere. Transport of Asian yellow sand dust (Kosa) is a well-known example. It travels over the Pacific Ocean and arrives in North America. In order to monitor atmospheric pollutants transported through free troposphere mountainous observation sites serve an important function. And, thus, atmospheric chemistry and physics studied at high mountains provides unique and important information. From such a point of view Symposium on Atmospheric Chemistry and Physics at Mountain Sites 2017 (ACPM2017) was held in Gotemba, Japan at the foot of Mt. Fuji in November, 2017.

This special issue aims to publicize the recent research on atmospheric chemistry and physics in the mountain environment and to get more information from the experts in the same research field, which includes observations, data analysis, and modeling. Six papers are accepted in this issue. We are indebted to all of the authors who have submitted original work to this issue. We are also thankful to the reviewers.

Shiro Hatakeyama

Niigata-shi, Niigata, Japan

25 May, 2019 